\title{
Factors that shape the elevational patterns of plant diversity in the Yatsugatake Mountains, Japan
}

\author{
Yoshitaka Oishi ${ }^{1}$ \\ ${ }^{1}$ Fukui Prefectural University
}

November 20, 2020

\begin{abstract}
Elevation is involved in determining plant diversity in montane ecosystems. This study examined whether the species distribution of plants in the Yatsugatake Mountains, central Japan, substantiated hypotheses associated with an elevational diversity gradient. Species richness of trees, shrubs, herbs, ferns, and bryophytes was investigated in study plots established at 200-m elevational intervals from 1800 to $2800 \mathrm{~m}$. The changes in plant diversity (alpha and beta diversities, plant functional types, and elevational ranges) with elevation were analyzed in relation to climatic factors and elevational diversity gradient hypotheses, that is, mass effect, mid-domain effect, and Rapoport's elevational rule. A comparison of alpha and beta diversities revealed that different plant groups respond variably to elevation; the alpha diversity of trees and ferns decreased, that of herbs increased, whereas the alpha diversity of shrubs and bryophytes showed a U-shaped relationship and a hump-shaped pattern. The beta diversity of shrubs, herbs, and bryophytes increased above the subalpine-alpine transition ecotone. In accordance with these changes, the dominance of evergreen shrubs and graminoids increased above this ecotone, whereas that of evergreen trees and liverworts decreased. None of the plant groups showed a wide elevational range at higher elevations. These elevational patterns of plant groups were explained by climatic factors, and not by elevational diversity gradient hypotheses. These patterns were further influenced by plant-plant interactions via competition for light availability and physical habitat alternation.
\end{abstract}

\section{Hosted file}

Main_text_1120_2020.pdf available at https://authorea.com/users/357470/articles/494075factors-that-shape-the-elevational-patterns-of-plant-diversity-in-the-yatsugatakemountains-japan 

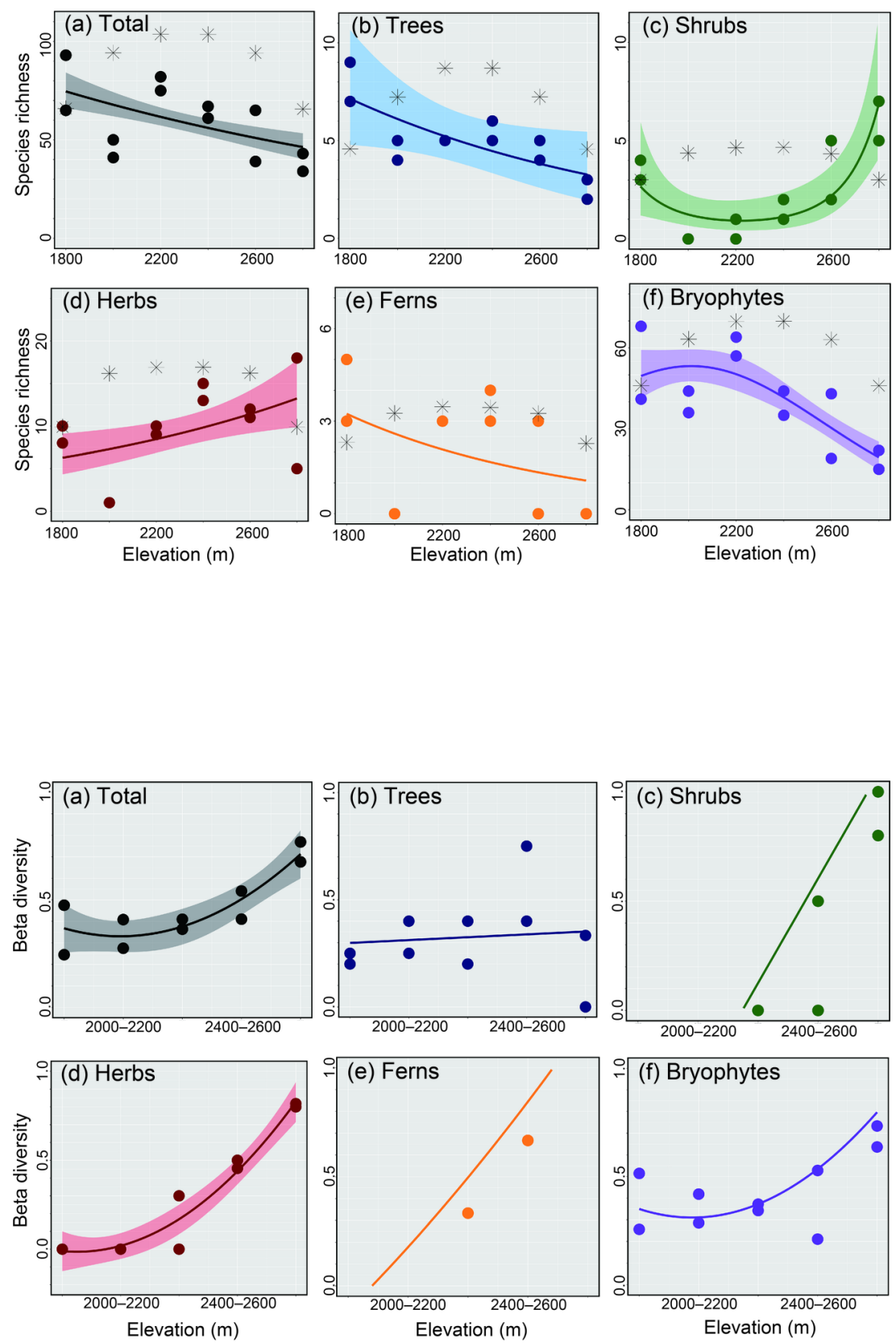

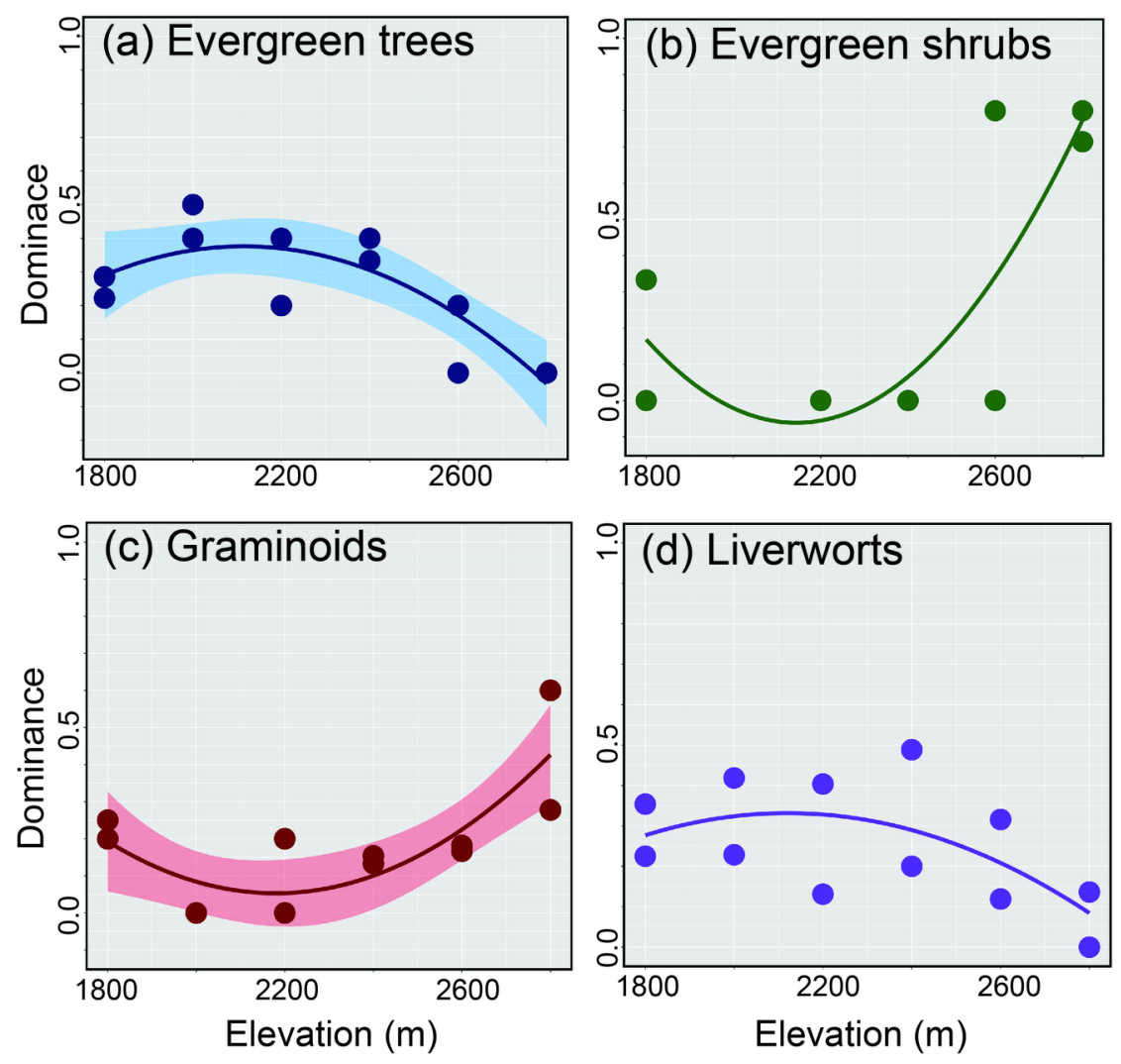

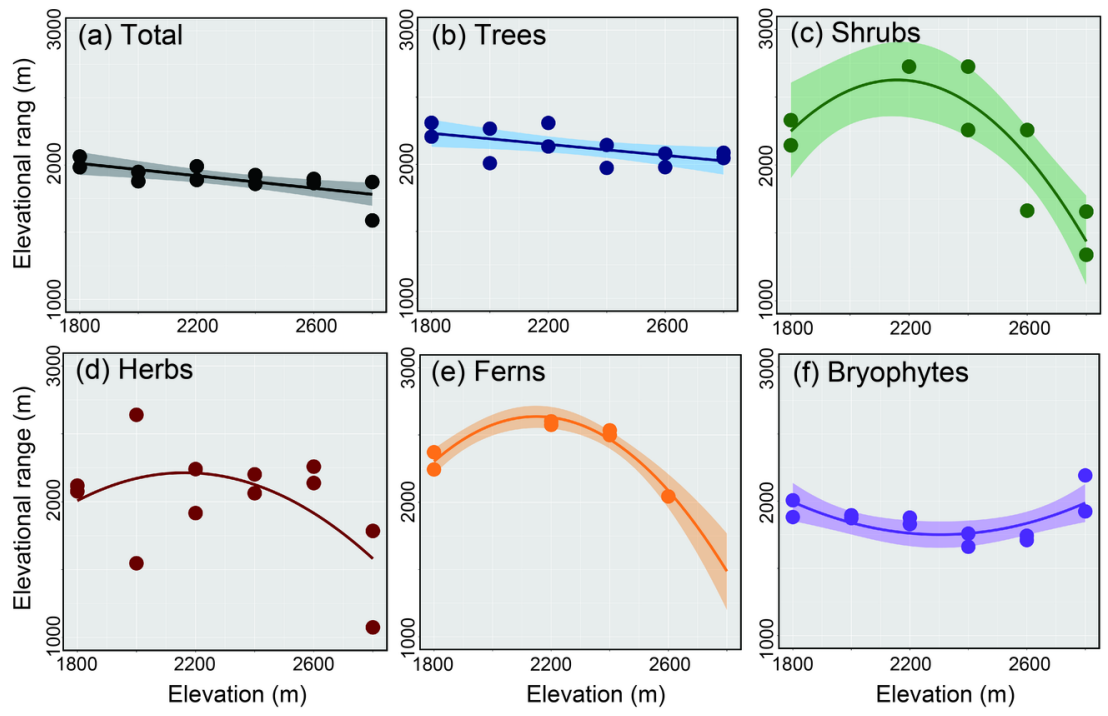